\title{
New Disease Reports \\ Carrot as a new host for a begomovirus: yellow mosaic disease of carrot reported in India
}

P.N. Sivalingam, K.V. Sumiya and V.G. Malathi*

Plant Virology Unit, Division of Plant Pathology, Indian Agricultural Research Institute, New Delhi 110012, India

*E-mail: vgmalathi@gmail.com

Received: 16 Jan 2011. Published: 29 Jun 2011. Keywords: Daucus carota, Tomato leaf curl New Delhi virus, ToLCNDV

Carrot (Daucus carota) is one of the important root vegetables grown in India during winter months (November to February). Since 2005 symptoms resembling those of yellow mosaic disease were observed in carrot plants in cultivators' fields and in kitchen gardens in the states of Uttar Pradesh, Delhi, Haryana and Punjab with an incidence of 30-40\%. The yellow vein symptoms start from the leaf margins and intensify gradually until the entire lamina appears yellow within a week (Fig. 1). In addition, some of the severely affected plants showed reduced lamina size and mild curling. Crude sap extracted from symptom-bearing plants in 100 $\mathrm{mM}$ Tris- $\mathrm{HCl}(\mathrm{pH}$ 8.0) produced leaf crinkling and leaf deformation symptoms after inoculation onto three-week-old seedlings of Nicotiana benthamiana. Healthy carrot plants produced yellow mosaic symptoms within 25 days after whitefly transmission from the diseased carrot plants. Electron microscopic observation of leaf dip preparations both from $N$ benthamiana and carrot revealed the presence of geminate particles $(18 \mathrm{x}$ $30 \mathrm{~nm}$ ). Carrot leaf extracts from all different locations readily reacted with a polyclonal antibody to African cassava mosaic virus in DAS-ELISA tests. Total nucleic acid was extracted from both infected and healthy leaf samples by Gem-CTAB method (Rouhibakhsh et al., 2008) and was tested in nucleic acid spot hybridisation tests using a radiolabelled probe to DNA A of Tomato leaf curl New Delhi virus - [Potato] (ToLCNDV-[IN:Mer:Pot2:2007]). Positive signals were seen for all plants showing different stages of symptoms. PCR amplification was done using coat protein gene specific primers to ToLCNDV-Pot (PotAF, 5'-GTGAAGCGACCAGCAGAT-3';

PotAR,

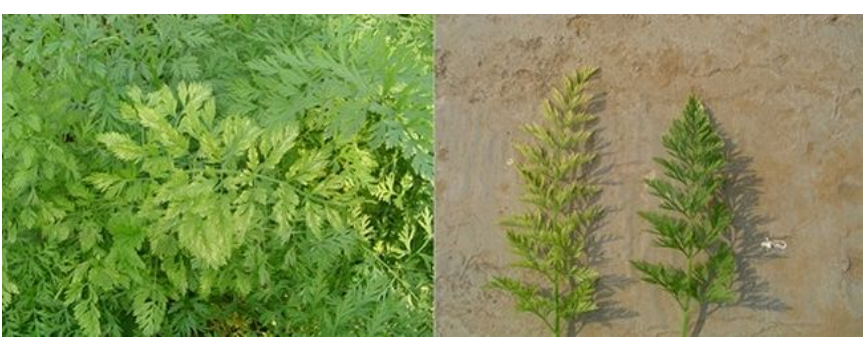

Figure 1
5'-TTAATTTGTTACCGAAT CATA-3') (Usharani et al., 2004). All the plants showing yellow mosaic symptoms yielded the expected amplicon of 750 bp length, and no such amplifications were observed with DNA extracted from apparently healthy plants (Fig. 2). The amplified products were cloned and sequenced (GenBank Accession No. EU224371). Sequence analysis (638 nucleotides of the fragment's 3 ' portion) revealed that it had $95-99 \%$ identity with various isolates of ToLCNDV, with a maximum of $99 \%$ with ToLCNDV-[Potato-Hapur]. This communication constitutes the first report of a begomovirus in the host carrot.

\section{References}

Rouhibakhsh A, Priya J, Periasamy M, Haq QMI, Malathi VG, 2008. An improved DNA isolation method and PCR protocol for efficient detection of multicomponents of begomovirus in legumes. Journal of Virological Methods 147, 37-42. [doi:10.1016/i.jviromet.2007.08.004]

Usharani KS, Surendranath B, Paul-Khurana SM, Garg ID, Malathi VG, 2004. Potato leaf curl - a new disease of potato in northern India caused by a strain of Tomato leaf curl New Delhi virus. Plant Pathology 53, 235. [doi:10.1111/j.0032-0862.2004.00959.x

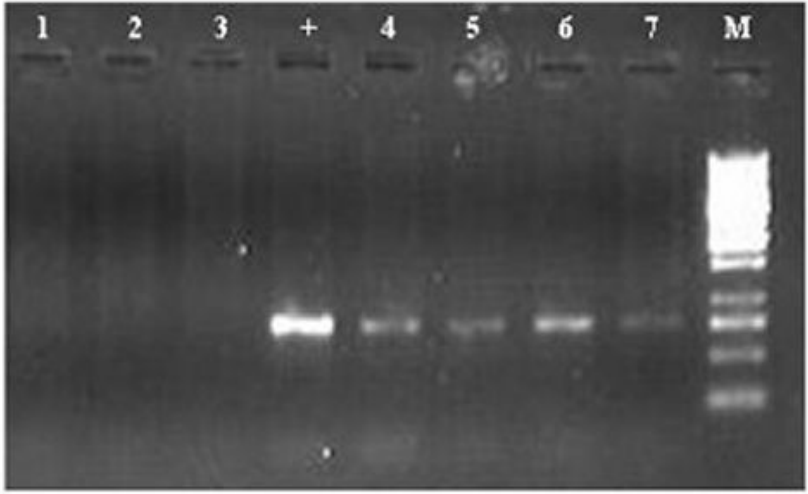

Figure 2

To cite this report: Sivalingam PN, Sumiya KV, Malathi VG, 2011. Carrot as a new host for a begomovirus: yellow mosaic disease of carrot reported in India. New Disease Reports 23, 34. [doi:10.5197/].2044-0588.2011.023.034] 